10 años de la despenalización de la dosis personal

\title{
Políticas públicas en materia de consumo de drogas psicoactivas: un paralelo entre los casos colombiano y holandés
}

Abogado especialista en Derecho Constitucional de la Universidatl de Paris II. Master en Instituciones y.Políticas Públicas de la Sorbona de Paris. Doeente de la Universidad Surcolombiana.

\section{Presentación preliminar}

1 análisis de las políticas públicas es una disciplina relativamente nueva en la ciencia política. Permite examinar al Estado en movimiento a partir de actuaciones concretas. Este examen permite considerar al gobierno, como un conjunto de procesos concretos en los cuales están comprometidos directa o indirectamente los elegidos y la administración pública, las organizaciones profesionales $y$ sindicales, los grupos de interés, etc. ${ }^{1}$. En otras palabras, el análisis de políticas públicas se concibe como una metodología de investigación social aplicada al examen de la actividad concreta de las autoridades públicas. El objetivo del estudio de caso que se presenta a continuación, ha consistido en exponer sucintamente los rasgos diferenciales de las políticas públicas en materia de drogadicción de los casos colombianos y holandés, que en principio parecen tener puntos coincidentes pero que presentan amplias diferencias en su desarrollo y resultado.
German Alfonso López Daza

\section{Introducción}

Desde la declaratoria de inconstitucionalidad de los artículos 51 y 87 de la Ley 30 de 1986 y la despenalización del consumo de la dosis personal de droga por parte de la Corte Constitucional (sentencia C-221 del 5 de mayo de 1994), el Estado colombiano ha abordado desde diferentes ópticas, las políticas públicas para el control del consumo de sustancias psicoactivas.

Los dos últimos gobiernos han tenido como prioridad.dentro de su agenda legislativa, la presentación de proyectos de reforma constitucional tendientes a la penalización del consumo de la dosis mínima y de esta forma corregir los efectos dejados por la sentencia de la Corte Constitucional. Sin embargo, hasta la fecha no se ha logrado sacar adelante este cometido.

Recientemente, el Congreso de la República a iniciativa del Gobierno Nacional, aprobó la Ley 745 del 19 de julio de 2002 , mediante la cual se

${ }^{1}$ LAGROYE, Jacques. Soclologie Politique. Presse de Science Po et Dalloz, Paris, 1997, 3ème édition, pag. 451 . 
tipificó como contravención, el consumo y porte de la dosis personal de estupefacientes o sustancias que producen dependencia con peligro para los menores de edad.

Sin embargo, nuevamente la Corte Constitucional intervino en la intención del Gobierno Nacional a través de la sentencia C-101 del 10 de febrero de 2004, la cual declaró la inexequibilidad del procedimiento que debían seguir los jueces penales y promiscuos municipales al asumir el conocimiento de la contravención por consumo y porte de la dosis personal de droga. Esta situación ha generado controversia, pues la citada ley ha quedado sin mecanismos para operar, debido al vació legal generado por el fallo de la Corte. Ante este panorama, se ha puesto en entredicho la política colombiana en materia de prevención y control del consumo de drogas.

La despenalización de la dosis mínima personal en 1994, puso a Colombia en la misma dirección de países con reconocida liberalidad en materia de políticas de drogadicción como Holanda, Alemania, Italia, Dinamarca o Canadá.

Sin embargo, a diferencia de lo que ocurre en dichos países, Colombia ha definido derroteros diferentes y los resultados después de 10 años de políticas basadas exclusivamente en la educación, no han sido las mejores. El aumento del consumo interno ha aumentado en forma constante desde 1996 y los esquemas o programas de acción estatal no han dado los resultados esperados.

El presente trabajo analizará la política pública colombiana en materia de prevención y control del uso de la dosis personal. Para ello, se hará como marco de referencia la política holandesa en esta materia y finalmente se tratará de establecer las posibles falencias en la política pública colombiana.

Características distintivas de la política holandesa en materia de drogas $^{2}$

Dentro del concierto europeo, Holanda siempre se ha caracterizado por ser un país muy liberal en materia de políticas públicas frente a temas sociales bastante complejos como la prostitución, la eutanasia o el consumo de estupefacientes.

En materia de drogadicción, desde hace más de 30 años, Holanda ha venido implementando políticas bien definidas tendientes a hacer frente al consumo de drogas entre su población.

La política aplicada en el tema de drogas, ha estado dirigida hacia el mantenimiento del control, o al menos hacer controlable, el consumo de drogas tomando en cuenta el riesgo como problema sanitario y social. Según este objetivo, la política holandesa de la droga ha alcanzado buenos resultados.

El consumo de las drogas en Holanda no ha sido mayor del que se daba ya

${ }^{2}$ Información suministrada por el servicio cultural de la Embajada de Holanda en Bogotá. Diciembre de 2003. 
en los años setenta y médicamente hablando, tampoco ha sido grave. Desde el punto de vista sanitario, tanto el consumo de alcohol como el de cigarrillo conllevan un precio incomparablemente mucha más alto que el consumo de todas las drogas juntas.

Siguiendo el ejemplo del dictamen del Grupo de Trabajo de narcóticos (1972), el gobierno holandés de entonces no vio ningún motivo para adoptar como punto de partida el hecho de que cada consumo de las mencionadas drogas incluye ya de por sí inaceptables riesgos colectivos.

Tal dictamen depende de las circunstancias bajo las cuales se desarrolla y del grado en que el consumo tiene lugar. Con base en esta consideración se eligieron, como objetivo central de la política, la prevención y el control de los riesgos colectivos e individuales que emanan del consumo de drogas.

La así formulada política holandesa de la droga ha permanecido inalterada desde entonces. Según esta propuesta, la administración pública tiene la misión de evitar en lo posible, que los ciudadanos (jóvenes especialmente), empiecen a consumir drogas. Esta política se materializa en la asistencia médica y/o social a los drogadictos problemáticos, con el objeto de aliviar sus apuros (la llamada reducción del mal).

A fin de establecer políticas públicas muy precisas para cada situación, Holanda ha definido y tipificado muy claramente dos tipos de drogas. Las ha clasificado en duras y blandas. Las drogas blandas son sustancias que causan muchos menos problemas para la salud; son cannabinoides (productos derivados de la planta del cáñamo) como la marihuana y el hachís. Las drogas duras son sustancias que conllevan un riesgo inaceptable para la salud, como la heroína, la cocaína y drogas sintéticas como las pastillas de éxtasis.

En 1976 se promulgó una ley en la materia, según la cual se estableció distinción entre drogas blandas y drogas duras. La distinción se funda en la convicción del gobierno de que las primeras no crean adicción. Y si bien el comercio de ambas es considerado ilícito, las autoridades toleran el de las blandas.

Esta división en "blandas" y "duras" es cuestionada por muchos estudiosos del tema ya que consideran que podría deducirse que las "duras" son malas y, por consiguiente, las "blandas" son buenas o menos malas y no es así, ya que a partir de determinadas dosis y según la forma de ser administradas, las drogas "blandas" pueden tener efectos tan nocivos como las "duras" ${ }^{3}$.

Esta distinción está basada en los riesgos que estas drogas conllevan para la salud del consumidor. Por ello, la tenencia en Holanda de drogas blandas (hasta 30 gramos) no se considera delito grave sino infracción. Bajo condiciones muy estrictas, no está penalizada la venta de drogas blandas en lugares autorizados o comúnmente llamados "coffeeshops".

${ }^{3}$ RUDGLEY, Richard. Enciclopedia de las sustancias psicoactivas. Argentina, 2002 Pág. 68. 
El objetivo de esta política es evitar que los adictos a las drogas blandas queden marginados o que entren en contacto con otras drogas más peligrosas. La idea es que un consumidor de cannabis que compra el producto a un traficante ilegal, tiene más posibilidades de entrar en contacto con las drogas duras.

Al separar el comercio de drogas duras y de drogas blandas, puede protegerse a los consumidores de drogas blandas de otras formas de consumo de drogas, mucho más dañinas desde el punto de vista sanitario. La otra cara de la moneda es la persecución estricta de la posesión y la venta de drogas duras.

Según la visión holandesa, los intereses a proteger mediante la penalización de esta actividad son primariamente la salud pública. Por consiguiente, la política sobre la droga ha sido diferenciada en Holanda, según el grado de gravedad del daño de salud potencial que se origina con el uso o abuso de las drogas en cuestión.

El objetivo principal de la política holandesa con respecto a las drogas, es reducir la oferta y demanda y minimizar los riesgos del consumo de drogas para el individuo, protegiendo de esta forma a la sociedad. Visto desde este punto de vista, las drogas blandas requieren un planteamiento distinto al de las drogas duras. En muchos otros países no se hace formalmente una distinción entre drogas duras y blandas, pero en la práctica sí se aplica tal diferencia.
La política holandesa con respecto a los toxicómanos va dirigida a limitar el riesgo y el daño y con ello, a la integración social de los drogadictos. La prevención, la asistencia ambulatoria e intramural están en manos de colaboradores expertos que trabajan en el seno de organizaciones dirigidas por profesionales. En Holanda se destinan aproxidamente unos 100 millones de dólares en la atención de drogadictos (en clínicas y centros de asistencia ambulatoria, entre otros). Comparado con otros países, la suma es bien importante.

La asistencia a drogadictos no va dirigida exclusivamente a alcanzar una abstinencia total con todos los adictos, es decir a la deshabituación completa de los ex-adictos, sino que aspira, con relación a los grupos meta descritos ulteriormente, al mejoramiento de su situación médica y a su funcionamiento social, ofreciéndoles por ejemplo facilidades médicas, suministro de metadona, canje de jeringuillas y formas de acogida diurna y nocturna.

Este programa de suministro de jeringuillas y agujas a cambio de las usadas se hace especialmente con el fin de prevenir el SIDA, entre otras enfermedades contagiosas. Con esta medida se ha logrado que el número de toxicómanos contagiado con el virus de inmunodeficiencia adquirida sea relativamente bajo en Holanda.

Algunos municipios holandeses suministran las jeringuillas en farmacias o autobuses especialmente 
acondicionados para tal fin. Esos autobuses se encuentran estacionados en lugares fijos $y$ en ciudades grandes como Ámsterdam o Rotterdam.

También se suministra gratuitamente la metadona, un opiácido sintético que se utiliza como sustituto de la heroína. Aunque la metadona también crea dependencia, no acarrea tanto riesgos como la heroína. La posibilidad de morir por una sobredosis de metadona es relativamente baja; además disminuye la frecuencia del uso de drogas. Como consecuencia de un menor consumo de drogas duras, se registra un mejoramiento físico de los drogadictos y al mismo tiempo una reducción de la criminalidad.

Dado que los toxicómanos no tienen por qué temer una persecución criminal ni la estigmatización social por antecedentes penales por el consumo de drogas, les resulta más fácil hacer uso de esta ayúda. Para los drogadictos es preferible escoger urr tratamiento médico en vez de sufrir una pena privativa de libertad.

En los tratados internacionales no se menciona el consumo de drogas como un acto que ha de ser sancionado. En otros países de la Unión Europea (UE), como por ejemplo Alemania, Italia y Dinamarca, tampoco se penaliza el consumo de drogas. El consumo de drogas en Holanda no suele ser, por lo demás, un fenómeno generalmente aceptado. Es desalentado, entre otras cosas, por la información que se da en las escuelas y mediante campañas acerca de los riesgos de las sustancias que crean dependencia (incluidos el alcohol y la nicotina).
Por medio de una política de asistencia y prevención profesional, se intenta disminuir la demanda de drogas y se reducen los riesgos para el individuo y su entorno directo. La lucha contra la oferta de drogas se desarrolla combatiendo activamente la criminalidad organizada. La política también está encaminada a mantener el orden público y a evitar las molestias sociales que conlleva el consumo de drogas.

Críticos del tema aseguran que aplicando este tipo de políticas, es más fácil pasar del consumo de drogas blandas al consumo de drogas duras. Sin embargo, según estadísticas del Gobierno holandés, sólo un pequeño porcentaje de consumidores de drogas blandas en Holanda pasa a consumir drogas duras. El número de adictos a opiáceos (como heroína, morfina y metadona) es relativamente bajo y no ha aumentado desde hace años; estas cifras revelan que la cantidad de adictos a estas drogas duras es inferior al número de adictos al cannabis. No existe ningún indicio de que el consumo de drogas duras sea estimulado por la política que se aplica a las drogas blandas.

Dentro de las directrices holandesas para prevenir el consumo de estupefacientes, la mayor prioridad la constituye la juventud. Durante la enseñanza primaria se presta especial atención a los riesgos de la droga, el alcohol, el tabaco y los juegos de azar. Se han puesto en marcha proyectos como Diversión y Drogas o campañas como La Escuela Sana y los Estimulantes. En este plan se informa sobre todos los tipos de estimulantes. Los escolares reciben 
charlas de especialistas cuando ya han alcanzado una edad en la que pueden entrar en contacto con la droga.

La administración holandesa presta ayuda" incluso a los drogodependientes que no desean dejar de serlo. Para las personas que se muestren contrarias a lä deshabituación o no logran una abstinencia, se pone especial atención en estabilizar la dependencia. De esa manera se evita que el consumo de las drogas duras origine en el consumidor, graves problemas de salud o la propagación de enfermedades por el uso común de agujas u otros utensilios.

Desde $1^{\circ}$ de septiembre de 2003, los enfermos crónicos en Holanda pueden obtener marihuana en la farmacia, con receta médica. El Estado holandés ha contratado a varias personas para el cultivo de la hierba. El canabis del Estado, está a disposición de pacientes de SIDA y de cáncer que sufren muchos dolores o_mareos como consecuencia de la quimioterapia, así como de enfermos de esclerosis múltiple y otros males que causan dolores intensos.

Por más divididas que estén las opiniones acerca de la política de la droga, existe un amplio consenso acerca del criterio final, según el cual puede juzgarse la efectividad de cada política nacional.

Política Pública holandesa en materia de venta de droga

En principio y según se ha fijado en materia de políticas pública en Holanda, la droga no está legalizada en este país. Las siguientes actividades, tanto por lo que respecta a las drogas blandas como a las duras, son punibles en Holanda.

\section{Tráfico (importación/exportación) \\ Venta libre \\ Producción \\ Tenencia}

El consumo de drogas en Holanda, como en muchos otros países, no es punible de por sí. El consumidor de drogas duras es considerado más como un paciente que como un criminal.

El Estado holandés considera el consumo de drogas blandas, como un asunto de pleno riesgo. Sin embargo, debido a la menor gravedad de los riesgos que encierra, la estrategia de control se ha matizado en relación con las drogas duras. La posesión de una cantidad de drogas blandas para autoconsumo ha sido despenalizada, tal como ocurre en algunos estados de los Estados Unidos y otros países. De este modo, el legislador ha subrayado que el planteamiento penal del consumo de drogas blandas no tiene que conducir a una estigmatización y a una marginalización social de los consumidores.

La política holandesa con relación al consumo de cannabis, está basada en la suposición de que una transición eventual del consumo de drogas blandas al de drogas duras se debe más bien a causas sociales que fisiológicas. Si los adultos jóvenes quieren consumir drogas blandas -y la experiencia ha demostrado que existe realmente esta necesidad entre grandes grupos- es mejor que lo hagan, según la visión holandesa, en un marco dentro del 
Políticas públicas en materia de consumo de drogas psicoactivas: un paralelo entre los casos...

cual no entren a la vez en contacto con la subcultura criminal que existe en torno a las drogas duras.

Tolerando una oferta que incluya una adquissición relativamente fácil de pequeñas cantidades de drogas blandas para autoconsumo, se aspira a mantener separados entre sí los mercados de consumidores de drogas blandas y drogas duras, quedando elevada de este modo la barrera social para la transición del consumo de drogas blandas al de drogas duras.

En la práctica, este punto de partida ha conducido a que la justicia tolere la venta de drogas blandas en los llamados coffeeshops (bares-tiendas) donde se venden drogas blandas a personas mayores de edad. La política relativa a los coffeeshops está bajo el signo de la "reducción del mal".

Esta política de tolerancia significa que los coffeeshops pueden vender drogas blandas, en cantidades máximas de 5 gramos por cliente. Además, en caso de ciertas enfermedades es posible adquirirlas como sedante, para lo cual se requiere una autorización especial.

Las autoridades holandesas defienden el principio de que el consumo de drogas blandas no necesariamente conduce al de las duras. Al tolerar su venta en los coffeeshops, el Gobierno intenta extraer las drogas blandas del circuito criminal y al parecer lo está logrando. Según la agencia nacional encargada de observar el consumo de drogas, Holanda cuenta con la menor cantidad de casos problemáticos de consumidores de drogas. Y en lo tocante al consumo en Europa, Holanda se encuentra en el sector intermedio.

En el año 2002 los coffeeshops holandeses cumplieron treinta años de existencia. Estos establecimientos en los que se venden drogas blandas, son uno de los principales atractivos para los turistas que visitan Holanda. $\mathrm{Y}$, como después de tres décadas los holandeses empiezan a perder interés, los turistas son los principales clientes.

Si bien en un coffeeshop se puede beber café, sus clientes muestran gran interés por la marihuana o el hachís. El turista medio puede llevarse una sorpresa, pues un coffeshop no es un bar común y corriente.

A pesar de que bajo la perspectiva internacional la situación no es desfavorable en términos de salud pública, el consumo de drogas constituye también en Holanda un problema social y administrativo de gran dimensión. Al abordar el problema se presentan tres complicaciones: la problemática de la molestia, la criminalidad organizada en torno al tráfico de drogas y la crítica extranjera sobre los supuestos y reales efectos externos.

En primer lugar, una pequeña parte de los adictos a la droga dura causa mucha molestia a sus conciudadanos. Este grupo comete gran cantidad de delitos patrimoniales a fin de conseguir dinero para la compra de sus estupefacientes. Contrariamente a lo que se esperaba, el suministro de metadona fácilmente adquirible, 
apenas ha producido un mejoramiento de la situación. Aproximadamente el 20 por ciento de los drogadictos muestra un estilo de vida de indigente. Su conducta vagabunda, su (poli) drogotependencia y criminalidad constituyen elementos que se fortalecen mutuamente.

La política holandesa en materia de drogas ha sido blanco de críticas en Europa. Con su plan de acción contra las drogas, Europa se ha propuesto combatir el problema. Por una parte, la iniciativa ofrece información y ayuda a drogadictos. Al mismo tiempo, combate el narcotráfico y la producción de drogas. Además, los tratados en el marco de las Naciones Unidas prohíben el comercio, la producción y el transporte de marihuana.

A pesar de ello, Holanda recibe creciente apoyo de otros Estados de la Unión" Europea , entre ellos Dinamarca, Alemania, Bélgica y Francia. Gradualmente, estos países siguen el ejemplo holandés, e incluso Inglaterra ha iniciado experimentos con coffeeshops. Por último, Suiza, que no pertenece a la Unión, también aplica una política de tolerancia.

En los últimos años, el parlamento holandés se ha pronunciado a favor de la legalización del uso del hachís y de la marihuana con fines medicinales. Tras la legalización de la eutanasia y la prostitución, Holanda vuelve a aparecer como el país polémico de Europa. Sin embargo, lo cierto es que Holanda anda a la par con otros países de Europa.
El caso colombiano: de la absoluta prohibición legal a la permisión por vía jurisprudencial

Antes de Ia Constitución Política de 1991, tanto la producción como el consumo de droga estaban penalizados. Era tan delincuente quien producía y comercializaba sustancias psicoactivas como quien las consumía. En 1994, dos años después de haber entrado en funcionamiento la Corte Constitucional, este Alto Tribunal declaró inconstitucional la norma que punía el consumo de dosis personal de droga. A partir de este momento, la política colombiana en materia de drogadicción ha debido tomar otro rumbo.

A pesar de que la intención del Estado ha sido la de volver a penalizar el consumo de droga, ante la imposibilidad de llevar a cabo esta reforma, los dos últimos Gobiernos han debido trabajar y desarrollar otro tipo de políticas y estrategias, todas tendientes a cerrar lo mas posible, la brecha abierta por la Corte Constitucional.

Han sido muchos los esfuerzos económicos y humanitarios que ha realizado el Estado colombiano para enfrentar las dos caras del problema: el narcotráfico y el consumo. Los instrumentos legales puestos en práctica, los compromisos internacionales asumidos, los permanentes operativos policiales y militares, las innumerables decisiones judiciales adoptadas, las masivas campañas preventivas y de impulso al desarrollo alternativo, han estado financiadas con recursos provenientes del gobierno central y local. 
Políticas colombianas en materia de drogadicción

Las políticas de las administraciones Samper y Pastrana tuvieron objetivos similares pero en algunos casos con estrategias diferentes. En el siguiente cuadro se presentan los objetivos de política de ambos gobiernos:

\begin{tabular}{|c|c|}
\hline Gobierno Samper 1994-1998 & Gobierno Pastrana 1998-2002 \\
\hline $\begin{array}{l}\text { Fortalecimiento de la } \\
\text { administración de justicia }\end{array}$ & $\begin{array}{l}\text { Fortalecimiento jurídico e } \\
\text { institucional }\end{array}$ \\
\hline Control e interdicción & Reducción de oferta de drogas \\
\hline Desarrollo alternativo & Desarrollo alternativo \\
\hline Prevención y rehabilitación & Reducción de demanda \\
\hline \multirow{2}{*}{ Cooperación internacional } & Política internacional \\
\hline & Gestión ambiental \\
\hline
\end{tabular}

Fuente: DNE 2002.

Actualmente, dentro del Plan de Desarrollo 2002-2006 Hacia un Estado Comunitarion, la política para el control del consumo de droga se encamina hacia la creación de un SISTEMA NACIONAL PARA PREVENCIÓN DEL CONSUMO DE DROGA en el marco de la lucha contra el narcotráfico.

El objetivo de la creación de este Sistema es que las diferentes instituciones y entidades gubernamentales del orden nacional, regional y local se encarguen de coordinar, desarrollar y fortalecer las políticas, planes y estrategias de prevención del consumo de droga.

Podemos afirmar que el Gobierno nacional ha centrado su política de drogadicción, básicamente en tres aspectos:

Restricción del consumo de dosis personal y penalización a quienes expongan abierta y públicamente su dependencia al consumo, a través de la Ley 745 de 2002;
D Educación a través de campañas de prevención y concientización del peligro que encierra el consumo de droga.

Acompañamiento al drogadicto en procesos de desintoxicación. Sin embargo, la materialización de esta política ha encontrado dificultades de tipo económico.

Teniendo en cuenta que la declaratoria de inconstitucionalidad de algunos artículos de la Ley 30 de 1986 "legalizó" el consumo de la dosis personal, el Gobierno trató, a través de la. Ley 745 de 2002, restringir este consumo limitándolo de tal forma que no perturbe a la comunidad y a los menores.

Esta ley penalizaba el consumo de dosis personal de droga en precisas situaciones tales como:

En establecimientos educativos, o en lugares aledaños a estos o en el domicilio de menores; 
Consumo ante menores;

En lugares públicos o en establecimientos comerciales de esparcimiento;

Los infractores recibirían multas o arresto y la competencia para conocer de êštas contravenciones sería de los jueces penales municipales o promiscuos municipales.

Sin embargo, tal como se expresó anteriormente, la Corte Constitucional declaró inconstitucional el artículo 5 de esta ley que determinaba las competencias y remitía a una ley derogada (Ley 228/1995).

Ante esta situación, la política de la restricción del consumo de dosis personal ha quedado sin aplicación.

La base de las política pública del Estado colómbiano en materia de consumo de drogas psicoactivas, han estado basada principalmente en la educación y prevención, principalmente en los niños. La asistencia social, aunque también se da, se efectúa en menor intensidad.

La estrategia del Gobierno incluye, además, prevenir el consumo de droga desde el ámbito educativo, laboral, familiar y comunitario con la participación de la ciudadanía y las entidades gubernamentales y no gubernamentales que trabajan en el tema.
A esta política se suma:

E1 fortalecimiento de las medidas de control a los centros o instituciones de atención y prevención de droga.

$>$ Un mayor apoyo a la investigación, evaluación y sistemas de información, esencial en la toma de decisiones y seguimiento de políticas relacionadas con la prevención, tratamiento y rehabilitación de personas adictas a estas sustancias.

$>$ Continuar en la búsqueda de cooperación internacional para intercambiar experiencias con otros países en la implementación de políticas frente al consumo.

El consumo de drogas en Colombia ha venido en aumento. Mientras en 1996 se estimó que el $0,9 \%$ de la población entre 10 y 24 años había consumido cocaína alguna vez en la vida, en 1999 esta proporción ascendía a $3,5 \%$, y para 2001 llegaba al $4,5 \%^{4}$. El consumo de marihuana presenta un comportamiento similar: para 1996 un $5,4 \%$ de los colombianos en dicho rango de edad había probado esta droga al menos una vez en su vida, $y$ para 1999 lo había hecho el 9,2\%, cifra que permaneció constante hasta 2001. Además, en este periodo, el consumo de otras sustancias psicoactivas legales como el tabaco, el alcohol y los tranquilizantes creció en proporciones similares.

* Fuentes: Estudio Nacional sobre consumo de sustancias psìcoactivas Colombia, 1996. Dirección Kacional de Estupefacientes (18.770 personas encuestadas). Presidencia de la República, Programe Rumbos. Sondeo nacional de consumo de drogas en jóvenes de 10 a 24 años (305.869 persanas encuestadas). 1999. Ibídem, (200.876 personas encuestadas). 2001. 
Políticas públicas en materia de consumo de drogas psicoactivas: un paralelo entre los casos...

Entre 1995 y 1999, el Estado colombiano destinó aproximadamente $\$ 2.34$ billones de pesos de 1999 en la reducción progresiva y sistemática de la producción, fabricación, distribución, tráfico, consumo de estupefacientes y delitos relacionados con el narcotráfico, esto equivale a US\$1.48 millones de dólares. De estos recursos, $\$ 1.36$ billones (58.21\%) se orientaron a la Reducción de la Oferta de Drogas Ilícitas; \$613.6 mil millones (26.22\%) al Fortalecimiento Jurídico e Institucional; $\$ 221.1$ mil millones $(9.45 \%)$ al Desarrollo Alternativo; \$121.9 mil millones $(5.21 \%)$ a la Reducción de la Demanda de Drogas, \$19.7 mil millones $(0.84 \%)$ y $\$ 1.4$ mil millones $(0.06 \%)$ a Gestión Ambiental y a la Política Internacional respectivamente.

Este panorama empeora con la entrada al mercado colombiano de las llamadas drogas sintéticas como el éxtasis, cuyo poder adictivo es mucho mayor al de las drogas de origen natural y la facilidad de su producción y tráfico aumenta el riesgo de incrementar su consumo. El costo asociado con el consumo de drogas, generado por la pérdida de capital humano, pérdida de productividad laboral y escolar, gastos en atención de emergencias y tratamiento, se estima en $\$ 750.790$ millones de pesos ${ }^{5}$.

A fin de poder enfocar de mejor forma la ejecución de la política colombiana en materia de drogadicción, el Estado cuenta con varias entidades que se han especializado en el manejo de este tema. Tales entidades son:
Consejo Nacional de Estupefacientes

Es el organismo rector de la política nacional de drogas. El Consejo Nacional de Estupefacientes -C.N.E.- fue creado por el Decreto 1206 del 26 de Junio de 1973 como un órgano asesor del Gobierno Nacional con el objetivo de formular, para su adopción, las políticas, los planes y programas que las entidades públicas y privadas deben adelantar para la lucha contra la producción, comercio y uso de drogas o sustancias que producen dependencia física o síquica. Igualmente, propone medidås para el control del uso ilícito de tales drogas o sustancias.

\section{Dirección Nacional de Estupefacientes}

Fue creada con el fin de coordinar el desarrollo y ejecución de las políticas en materia de control, prevención y represión de estupefacientes. El artículo 93 de la Ley 30 de 1986 , señala que la oficina de estupefacientes del Ministerio de Justicia hará las veces de secretaría ejecutiva del Consejo. Su misión principal es la de ejecutar las decisiones del Consejo Nacional de Estupefacientes.

RUMBOS, Programa Presidencial para afrontar el consumo de drogas

Mediante Decreto127 del 19 de enero de 2001, el Gobierno colombiano creó el Programa Presidencial Rumbos, para afrontar el consumo de drogas. Este programa establece como principios, el de la prevención integral del consumo

\footnotetext{
${ }^{5}$ Cálculos de la Dirección de Justicia y Seguridad, Departamento Nacional de Planeación.
} 
de sustancias psicoactivas mediante procesos tendientes al desarrollo humano a través de la formulación y ejecución de un conjunto de políticas y estrategias tendientes a promover el fortalecimiento de la capacidad de las comunidades para comprender e intervenir globalmente en la reducción del consumo de sustancias psicoactivas (S.P.A.) y problemas asociados, ofreciendo entre otras alternativas, las de tipo preventivo, terapéutico y de reinserción social.

Este Programa debe establecer canales de enlace para que los Ministerios de Educación Nacional, Salud, Comunicaciones, Trabajo y Seguridad Social y el Instituto Colombiano de Bienestar Familiar, entre otros, incluyan dentro de sus programas la prevención integral del consumo de sustancias psicoactivas y realicen el debido seguimiento a sus metas; de manera especial, los que tengan como usuarios o beneficiarios a la niñez y la juventud.

Igualmente, busca fortalecer el intercambio de experiencias con entidades y organismos nacionales e internacionales, oficiales y no gubernamentales, así como el desarrollo conjunto de programas de tratamiento de niños y jóvenes consumidores de sustancias psicoactivas. El Programa
Rumbos no tiene funciones operativas sino conceptuales, por eso su balance no es numérico.

Adicionalmente, se han buscado fortalecer las medidas que controlen a los centros o instituciones de atención, tratamiento y rehabilitación integral del consumo de sustancias psicoactivas, tanto públicas como privadas. Se ha impulsado la investigación, la evaluación y los sistemas de información, esenciales en la toma de decisiones y seguimiento de políticas relacionadas con la prevención, tratamiento y rehabilitación. Finalmente, el Gobierno Nacional ha buscado la cooperación internacional, para intercambiar experiencias con otros países en la implementación de políticas frente al consumo.

\section{A nivel local (municipal o} departamental)

En la práctica se observa que las Secretarías de Salud Departamental y Municipal contratan con organismos o fundaciones especializadas, la atención de pacientes drogodependiente. Esta atención está dirigida a la asistencia, acompañamiento y rehabilitación del paciente. En casos severos en que exista compromiso de la salud (convulsiones, intoxicación), la atención se realiza a través de la red de hospitales públicos. 
Políticas públicas en materia de consumo de drogas psicoactivas: un paralelo entre los casos...

Cuaadro que resume la sitituación colombiana y holandesa

\begin{tabular}{|c|c|c|}
\hline & COLOMBIA & HOLANDA \\
\hline $\begin{array}{l}\text { Objetivo de la Política } \\
\text { Pública }\end{array}$ & $\begin{array}{l}\text { Restricción del consumo de } \\
\text { dosis personal y penalización } \\
\text { a quienes expongan abierta y } \\
\text { públicamente su dependencia } \\
\text { al consumo, a través de la Ley } \\
745 \text { de } 2002 \text {; } \\
\text { Educación a través de } \\
\text { campañas de preverición y- } \\
\text { concientización del peligro } \\
\text { que encierra el consumo de } \\
\text { droga. } \\
\text { Acompanamiento al drogadicto. } \\
\text { en procesos de desintoxicación. }\end{array}$ & $\begin{array}{l}\text { La prevención y el control } \\
\text { de los riesgos colectivos e } \\
\text { individuales que emanan } \\
\text { del consumo de drogas. } \\
\text { Mantener, bajo control o } \\
\text { hacer controlable, el } \\
\text { consumo de drogas tomando } \\
\text { en cuenta el riesgo como } \\
\text { problema sanitario y social. } \\
\text { Este objetivo se materializa } \\
\text { a través de la asistencia } \\
\text { directa al drogo dependiente, } \\
\text { buscando excluirlo de la } \\
\text { criminalidad y evitando que } \\
\text { consuma drogas duras } \\
\text { (suministro de jeringuillas, } \\
\text { drogas y programas de } \\
\text { resocialización). }\end{array}$ \\
\hline $\begin{array}{l}\text { Consumo de la dosis } \\
\text { personal }\end{array}$ & $\begin{array}{l}\text { Permitido bajo el soporte } \\
\text { constitucional del libre } \\
\text { desarrollo de la personalidad. }\end{array}$ & $\begin{array}{l}\text { Tolerado bajo la tesis del } \\
\text { mal menor. }\end{array}$ \\
\hline $\begin{array}{l}\text { Forma de adopción del } \\
\text { consumo de dosis } \\
\text { personal. }\end{array}$ & $\begin{array}{l}\text { A través de pronunciamiento } \\
\text { de la Corte Constitucional } \\
\text { en } 1994 \text {. No se produjo como } \\
\text { política de Estado. }\end{array}$ & $\begin{array}{l}\text { Adoptado como política de } \\
\text { Estado desde } 1972 \text {. }\end{array}$ \\
\hline Venta de droga. & $\begin{array}{l}\text { Prohibida y duramente } \\
\text { penalizada. }\end{array}$ & $\begin{array}{l}\text { Tolerada únicamente para } \\
\text { la denominada droga } \\
\text { blanda. } \\
\text { Su expendio se restringe a } \\
\text { los coffeeshops y a las } \\
\text { farmacias para los enfermos } \\
\text { que lo requieran (con } \\
\text { prescripción médica). }\end{array}$ \\
\hline Cultivo de droga & $\begin{array}{l}\text { Prohibida y duramente } \\
\text { penalizada. }\end{array}$ & $\begin{array}{l}\text { Permitido únicamente el } \\
\text { de la marihuana por parte } \\
\text { del Estado. }\end{array}$ \\
\hline $\begin{array}{l}\text { Comportamiento del } \\
\text { consumo. }\end{array}$ & En aumento. & A la baja. \\
\hline
\end{tabular}




\section{Conclusiones}

El consumo de drogas se ha convertido desde hace un tiempo, hacia el presente, en un analizador de las políticas públicas en materia de prevención. La reducción de daños define una política en relación a la salüad y a lo social que es relativamente nueva y que ha tomado fuerza en el mundo, fundamentalmente a raíz de la alta incidencia de la transmisión del HIV en los usuarios de drogas inyectables.

La política holandesa, a contrario de la colombiana, tiene por objetivo reducir los daños relacionados con las drogas, no focalizándolo por tanto en el consumo de drogas en sí mismo o en la abstinencia.

Los daños relacionados con las drogas son múltiples: en lo social y en la salud. Débemos reconocer que el SIDA produce daños mayores que los producidos por las drogas mismas. Sin embargo, la reducción de daños no es solamente programas de cambios de jeringas o programas de sustitución opiácea. Tal como lo ha concebido Holanda, es fundamentalmente garantizar el acceso de todos a la información y a la prevención, facilitar el contacto del drogodependiente con el sistema de salud y evitar definitivamente los costos sociales y subjetivos que acompañan a la penalización.

En Colombia, la lucha contra las drogas se ha enfocado principalmente en dos niveles: producción y consumo, dejando de lado aquellos factores que alimentan los conflictos de éxodo de población, pobreza y el desorden mundial, producto de este ilícito que avanza en todo el hemisferio.

El Estado colombiano siempre ha orientado su política penal, en criterios foráneos al problema. La experiencia colombiana evidencia cómo la penalización del consumo, la producción y el tráfico de estupefacientes esta llena de vacíos y contradicciones en su fundamentación. La tesis de un eventual aumento del consumo y aumento de los índices de violencia con una hipotética legalización, están hoy en đía revaluados o sometidos a una fuerte crítica por parte de los expertos en el tema.

En las políticas públicas de drogadicción, ha faltado coherencia en la estrategia y un verdadero interés político (traducido en apoyo económico) para erradicar de raíz la problemática. Colombia, con respecto a este problema, no tiene poder de decisión; sólo le queda avalar las políticas internacionales así sean dañinas para los colombianos, no importando la no obtención de los beneficios esperados.

Los Estados Unidos imponen sanciones verticalmente, contraviniendo todo principio internacional de soberanía y el principio de autodeterminación de los pueblos. Es evidente que nadie puede afirmar que la guerra contra las drogas sea un éxito, ni en el campo de la producción y el comercio ni en el consumo.

Este fenómeno se ha tratado de combatir mediante la penalización y represión invirtiendo cada vez más recursos físicos, de capital y humanos. Sin embargo, a pesar de esta estrategia, 
no han disminuido las áreas cultivadas de plantas de donde se extrae droga en países como Bolivia, Colombia, Perú, y países de América Central y el Caribe.

La disponibilidad de estas drogas ha venido aumentando y el número de consumidores no ha podido disminuirse. La corrupción y la inoperancia de la ley ante el poder económico de los grupos de narcotraficantes, ha sido el resultado visible del fracaso de la política represiva. Desde este punto de vista se abre la posibilidad de pensar en nuevos caminos de solución, ya que se afirma que la guerra contra las drogas produce más daños que beneficios aparte de ser una guerra perdida.

A partir de los pobres resultados de la política prohibicionista, se resalta que el Estado carece de autoridad para prohibir el uso de drogas con fines recreativos que no perturban el orden externo ni el desarrollo humano. Se podría pensar en una despenalización de la producción y del consumo de las sustancias psicoactivas manteniendo una regulación con medidas administrativas de salud publica y de policía. Sin embargo, la comunidad internacional y específicamente los Estados Unidos, lo impedirían a través de sanciones económicas.

Son más altos los niveles de consumo en países con políticas represivas. La política de la reducción del mal materializada en Holanda con los coffeeshops, es un buen ejemplo. La producción y el consumo bajo la égida estatal, junto con fuertes políticas educativas y de asistencia no pueden entenderse como una invitación al consumo. Sería necesario estudiar cómo seria esta regulación, á cuáles drogas se extendería, cómo podrían ser comercializadas, qué controles deberían establecerse, si se expenderían en cualquier día del año, en qué locales y si el Estado debería asumir la producción o si laboratorios o fábricas privadas lo podrían hacer. 